\title{
O CUSTO DE ABANDONO NAS EMPRESAS PETROLÍFERAS*
}

\author{
THE COST OF ABANDONMENT IN OIL INDUSTRIES
}

\author{
ODILANEI MORAIS DOS SANTOS \\ Mestrando em Ciências Contábeis da Faculdade \\ de Administração e Ciências Contábeis da \\ Universidade Federal do Rio de Janeiro - RJ \\ E-mail: odilaneisantos@terra.com.br
}

\author{
JOSÉ AUGUSTO VEIGA DA COSTA MARQUES \\ Professor Doutor da Faculdade de Administração \\ e Ciências Contábeis da Universidade Federal do \\ Rio de Janeiro - RJ \\ E-mail: joselaura@uol.com.br
}

\author{
PAULA DANYELLE ALMEIDA DA SILVA \\ Mestranda em Ciências Contábeis da Faculdade \\ de Administração e Ciências Contábeis da \\ Universidade Federal do Rio de Janeiro - RJ \\ E-mail: pauladanyelle@terra.com.br
}

\section{RESUMO}

As atividades petrolíferas são tipicamente de alto risco e, conseqüentemente, de altos prêmios, quando do sucesso do esforço exploratório. Nesse contexto, o custo de abandono é um componente fundamental em qualquer análise de viabilidade econômica de projetos de exploração e produção de óleo e gás. Tais custos são extremamente elevados e chegam a exceder, em alguns casos, aos investimentos incorridos para a construção da infraestrutura e instalação dos equipamentos necessários à produção. $O$ objetivo deste estudo é investigar o arcabouço teórico e normativo do reconhecimento contábil do custo de abandono na contabilidade das empresas petrolíferas, contribuindo para o entendimento adequado das informações contábeis dessas empresas. Para tanto, desenvolveu-se um estudo exploratório-descritivo das normas contábeis aplicáveis ao custo de abandono nas empresas petrolíferas. As estimativas do custo de abandono devem ser consideradas como parte dos custos capitalizados do ativo (poços, equipamentos e instalações), tendo como contrapartida no passivo, o valor correspondente às obrigações futuras do desmantelamento, remoção e restauração dos campos petrolíferos. Tal prática foi implementada pelo SFAS 143 para dar uniformidade às informações divulgadas pelas empresas do setor, ante a diversidade de práticas anteriormente existentes.

Palavras-chave: Custo de Abandono; E\&P; Contabilidade de Óleo e Gás; SFAS 143.

\begin{abstract}
Oil industry activities are typically hazardous. When exploratory investments succeed, great rewards are achieved. Therefore, abandonment cost is an essential component that must be contemplated in any economic feasibility analysis of oil and gas exploration and production projects. Such costs are extremely high and in some cases they can exceed the investments to build infrastructure and install equipments necessary for production. The main goal of this study is to investigate both the theoretical framework and the existing standards used by oil companies to recognize abandonment costs in their books in order to give a proper understanding on the accounting information produced by these companies. Abandonment costs valuation must be taken into consideration as part of the capitalized cost of assets (oil wells, equipments and facilities) giving rise to a liability account conveying the amount related to future obligations of dismantlement, removal and restoration of oil fields. Such practice has been implemented by SFAS 143 in order to provide uniformity to information released by oil industry companies.
\end{abstract}

Keywords: Abandonment Cost; E\&P; Oil and Gas Accounting; SFAS 143.

Recebido em 6.12.2005 • Aceito em 18.05.2006 • $2^{\mathrm{a}}$ versão aceita em 3.07.2006

* Artigo originalmente apresentado no IX Congresso Internacional de Custos, Santa Catarina, novembro/2005. 


\section{INTRODUÇÃO}

O registro da participação do petróleo na vida humana remonta a tempos bíblicos: na antiga $\mathrm{Ba}-$ bilônia, os tijolos eram assentados com asfalto e o betume era largamente utilizado pelos fenícios na calafetação de embarcações. Ao longo do tempo, o petróleo foi se impondo como fonte de energia, principalmente depois do advento da petroquími$\mathrm{ca}$, nas quais centenas de novos compostos, tais como: o plástico, as borrachas sintéticas, as tintas, os corantes, os adesivos, os solventes, os detergentes, os explosivos, os produtos farmacêuticos, os cosméticos etc., foram desenvolvidos (THOMAS, 2001).

Hoje, o petróleo representa a principal fonte de energia primária consumida no mundo e movimenta bilhões de dólares diariamente em atividades industriais gigantescas, passando a ser imprescindível às facilidades e comodidades da vida moderna.

A indústria do petróleo é caracterizada por ser tipicamente de capital intensivo, com altos riscos nas atividades de exploração, altos investimentos em desenvolvimento da produção, e longos prazos de maturação do investimento e, conseqüentemente, de altos prêmios, quando do sucesso do esforço exploratório.

$\mathrm{Na}$ cadeia produtiva das atividades de Exploração e Produção (E\&P), o custo de abandono faz parte dos seus macro processos básicos. Portanto, na análise da viabilidade técnica de um projeto de exploração e produção de óleo e gás, deve-se levar em conta desde os investimentos necessários para obtenção dos dados necessários ao estudo da área a ser explorada, até os custos de abandono quando do final da vida econômica do campo produtor de óleo e gás.

Os custos de abandono (desmantelamento, remoção e restauração do local) são, portanto, componentes fundamentais em qualquer análise de viabilidade econômica, uma vez que, em alguns casos, eles são extremamente elevados e chegam a exceder os investimentos incorridos para a construção da infra-estrutura e instalação dos equipamentos necessários a produção (JENNING, FEITEN e BROCK, 2000).

Nesse contexto, este trabalho se justifica pela representatividade do custo de abandono no custo total de produção de óleo e gás e contribui para à compreensão desses custos nas atividades petrolíferas. O objetivo, assim, é investigar o arcabouço teórico e normativo do reconhecimento contábil do custo de abandono na contabilidade das empresas petrolíferas, contribuindo para o adequado entendimento das informações contábeis dessas empresas.

\section{METODOLOGIA}

Conforme Gil (1996, p. 45), "a pesquisa exploratória tem como objetivo proporcionar maior familiaridade com o problema, com vistas a torná-lo mais explícito, construir hipóteses ou aprimorar idéias". Como no Brasil ainda não existe um conjunto de teorias e conhecimentos desenvolvidos e sistematizados sobre a contabilidade no setor petrolífero, especificamente para as atividades de exploração e produção (E\&P), este estudo se caracteriza como uma pesquisa exploratória.

Como o objetivo do estudo é investigar as bases teóricas e normativas que fundamentam a prática contábil dos principais aspectos relacionados ao tema, que são o reconhecimento, a mensuração e a evidenciação dos custos de abandono, o delineamento da pesquisa caracteriza-se como bibliográfica, na qual são descritas e comparadas as principais normas e práticas de contabilidade aplicadas às atividades de exploração e produção de óleo e gás.

Espera-se com este estudo estimular futuras pesquisas na área de oil and gas accounting, bem como fornecer fundamentação teórica para a aplicação empírica em empresas do setor petrolífero.

O arcabouço teórico e normativo da contabilidade do setor petrolífero refere-se, neste estudo, às normas e práticas de contabilidade e evidenciação norte-americanas, pois, conforme Godoy (2004), as práticas contábeis desenvolvidas por aquele país até hoje não foram superadas, tendo em vista a larga utilização pelas companhias de atuação em nível mundial, em função da necessidade de captação de recursos e da atuação no mercado norte-americano.

As limitações do estudo residem no fato de que alguns conceitos e abordagens integrantes da contabilidade das empresas petrolíferas não foram apresentados e/ou discutidos, uma vez que se restringiu aos assuntos intimamente ligados ao custo de abandono.

\section{OS CUSTOS DAS ATIVIDADES DE E\&P}

Basicamente, as atividades da indústria petrolífera estão divididas em dois segmentos: o de upstream, responsável pelas atividades de exploração e produção (E\&P), que tem por objetivo a obtenção do petróleo e gás natural e o segmento downstream, responsável pelas atividades de refino, transporte, comercialização e estocagem. As empresas que atuam nos dois segmentos são conhecidas como verticalmente integradas e as que atuam em apenas um dos segmentos, independentes. 
Considerando, apenas, a cadeia produtiva das atividades de uma empresa que atua no segmento de E\&P (figura 1), os custos incorridos nas atividades de exploração e produção de petróleo e gás são agrupados dentro de quatro categorias básicas: custos de aquisição, exploração, desenvolvimento e produção. Essa classificação está de acordo com - Regulation S-X, rule 4-10 da Securities and EXchange Commission (SEC) e com o SFAS n' 19 , do Financial Accounting Standard Board (FASB).

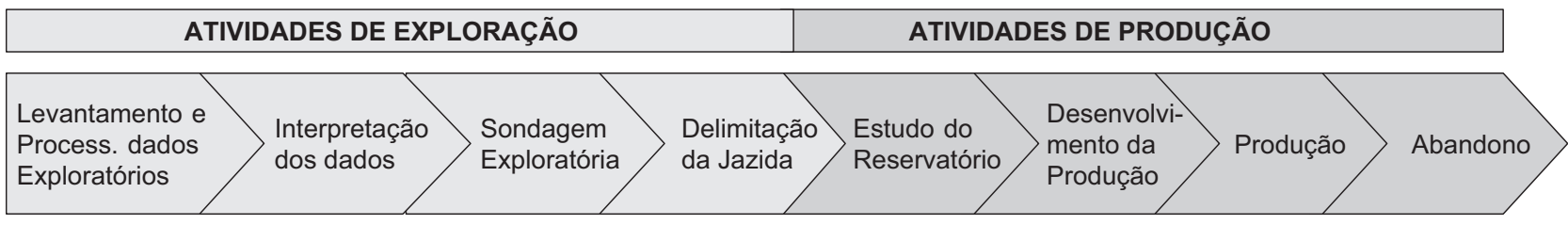

Fonte: Elaborada pelos autores.

Figura 1 - Cadeia Produtiva de uma Empresa de E\&P

Os custos de aquisição incluem os gastos incorridos para adquirir, alugar ou usar ou qualquer outra forma de aquisição dos direitos de uso de determinada área e ainda abrange bônus, taxas de agenciamento/intermediação, taxas de registro, custos legais e outros.

Os custos de exploração envolvem os gastos incorridos na identificação de áreas potenciais e nos exames específicos de áreas com potencial de reserva de óleo e gás natural, incluindo perfuração de poços exploratórios e de testes estratigráficos ${ }^{1}$, bem como gastos com estudos topográficos, geológicos e geofísicos. Os gastos de exploração podem ocorrer tanto antes como depois da aquisição da área ou mesmo incorridos sem que a área nunca seja adquirida.

Os custos de desenvolvimento são aqueles incorridos para obter acesso às reservas provadas e para prover instalações para extração, tratamento, recolhimento e estocagem do óleo e do gás natural e ainda os custos das instalações de produção, tais como: linhas de escoamento, separadores, tratadores, aquecedores, tanques de estocagem, sistemas de recuperação e instalações de processamento de gás natural.

Uma observação importante é que "ao contrário do que ocorre com os gastos de exploração, que estão relacionados às reservas não provadas, os gastos de desenvolvimento estão associados às reservas provadas de óleo e gás, portanto, que se conhecem por estimativas os benefícios futuros" (GODOY, 2004, p. 95).

Quanto aos custos de produção, são todos aqueles gastos incorridos em atividades para extrair ou elevar o óleo e gás natural para a superfície, bem como os gastos relacionados com a acumulação, tratamento, processamento e estocagem, no campo, do óleo e gás natural obtido. Conforme Silva (2004, p. 41), "são os custos incorridos para operar e manter poços, equipamentos e instalações, incluindo a depreciação dos mesmos. Incluem também a mão-de-obra para operar os poços e instalações, gastos de reparo e manutenção, materiais e suprimentos consumidos, impostos de produção e outros tributos".

A última atividade da cadeia produtiva petrolífera de E\&P diz respeito ao abandono da área produtora de óleo e gás. A caracterização dos diversos custos incorridos nessa etapa é descrita a seguir.

\section{O CUSTO DE ABANDONO NO SETOR PETROLÍFERO}

Nos projetos de produção de reservas de petróleo e gás natural é importante que seja levado em consideração, além dos investimentos iniciais com perfuração de poços, compra e instalação de equipamentos, construção de estação de coletas de petróleo, dentre outros, os custos inerentes ao desmantelamento, remoção e restauração das áreas produtoras de óleo e gás.

Além do mais, a importância do custo de abandono para as estratégias da empresa, quando analisado sob o enfoque do ciclo de vida do produto, é de importância fundamental. De acordo com Peres Jr., Oliveira e Costa (1999) e Cogan (2002), na análise do ciclo de vida é preciso levar em consideração todos os custos que incorrem no período útil de um produto/projeto, mesmos aqueles que incorrem bem antes da fase inicial dos processos produtivos (design de um produto, estudos de viabilidade, projetos de engenharia etc.) até aqueles referentes

1 Testes Estratigráficos: são os poços perfurados somente para se obterem informações geológicas do subsolo. 
ao abandono definitivo de sua produção e comercialização, descarte final de quaisquer resíduos ou mesmo até quando as obrigações inerentes perdurarem.

Horngren, Datar e Foster (2004, p. 400) explicam que nos produtos/projetos com ciclos de vida longos (como é o caso de um projeto de exploração e produção de petróleo), as decisões de projeto afetam os custos por vários anos, por isso é importante levar em consideração todos os custos que incorrem durante a vida útil. Exemplificam utilizando o caso de empresas que são obrigadas a restaurar o meio ambiente ou dar um destino seguro a seus produtos ao final da vida útil: "fabricantes de computadores laptop - por exemplo, Compaq e Apple - introduziram onerosos programas de reciclagem para se certificar de que as baterias de níquel-cádmio, que podem causar danos ao solo, sejam eliminadas de maneira ambientalmente segura."

Nesse contexto, de acordo com Epstein (1996), as empresas devem levar em conta os custos de descarte, abandono e reciclagem nos custos dos produtos e investimentos de capital. Para tanto, necessitam saber e rastrear os custos ambientais atuais e futuros.

Assim, Kaplan e Cooper (1998, p. 273) afirmam que, para minimizar esses custos futuros, as empresas devem primeiro entender a magnitude desses custos e os produtos e processos que contribuem para eles. "A falha no reconhecimento dos custos futuros de descarte, reciclagem e restauração poderá ocasionar a subestimação dos custos totais de produção dos produtos de hoje".

Nessa mesma linha, Atkinson (1990) argumenta que os custos no estágio de abandono podem ser elevados e o seu não reconhecimento durante a vida do produto/projeto pode levar a tomadas de decisões equivocadas.

Logicamente, este estudo não pretende analisar todo o ciclo de vida do petróleo, o que seria um trabalho hercúleo, mas apenas evidenciar a importância do custo de abandono no ciclo das atividades de exploração e produção de petróleo, mostrando sua particularidade.

Em se tratando desse segmento de atividade, à medida que o tempo vai passando, a produção de petróleo e gás vai decrescendo até o momento em que as receitas provenientes das vendas da produção são insuficientes para cobrir as despesas de manutenção da operação. Essa é a condição para o abandono do projeto (THOMAS, 2001, p. 196-197).
Quando o poço alcança o seu limite econômico, o mesmo deve ser retirado de operação e tamponado, de modo a isolar os fluídos das formações entre si e da superfície, visando minimizar os riscos de acidentes e danos ao meio ambiente. Todas as instalações e equipamentos montados no poço devem ser removidos. Além disso, a área deve ser recuperada para as condições existentes no período anterior à intervenção produtiva, de modo que o impacto no meio ambiente seja o mínimo possível.

Tratam-se, portanto, de custos inevitáveis que na indústria petrolífera incluem o desmantelamento, demolição ou desmontagem e a remoção de instalações e equipamentos utilizados na produção e, ainda, a restauração e recuperação da área para as condições ecologicamente similares às existentes antes do início da extração de petróleo e gás natural.

Conforme Jenning, Feiten e Brock (2000, p. 481), os custos de abandono, comumente referidos como dismantlement, restoration, and abandonment costs ou $D R \& A$ costs, são usualmente obrigações exigidas por meio de regulamentações governamentais, ou decorrem de obrigações contratuais.

No Brasil, por exemplo, a Agência Nacional do Petróleo (ANP), por meio da Portaria ANP $n^{\circ} 25$, de 6 de março de 2002, entende que o custo de abandono é aquele necessário para "assegurar o perfeito isolamento das zonas de petróleo e/ou gás e também dos aqüíferos ${ }^{2}$ existentes, prevenindo: I - a migração dos fluidos entre as formações, quer pelo poço, quer pelo espaço anular ${ }^{3}$ entre o poço e o revestimento; e II - a migração de fluidos até a superfície do terreno ou o fundo do mar".

Por meio da Portaria ANP $n^{\circ} 114$, de 25 de julho de 2001, a ANP definiu custo de abandono como "o processo constituído do abandono de poços e da desativação das instalações na área de concessão" e que desativação das instalações é o ato de "tirar de serviço ou de atividade, reverter, alienar ou remover, qualquer instalação construída em uma área de concessão, que teve como propósito original servir à exploração de petróleo ou gás natural, bem como recuperar as áreas ocupadas por esta instalação".

Os maiores custos de abandono ocorrem quando as áreas a serem abandonadas estão situadas no mar (offshore), na qual existe a necessidade de desmontagem dos equipamentos e outras estruturas dos poços (normalmente em ambientes hostis) e a recuperação da superfície oceânica.

Os custos do abandono offshore são extremamente elevados e em alguns casos excedem

\footnotetext{
2 Aqüífero: intervalo permeável contendo água de qualquer natureza, passível de ser destinada ao uso público ou industrial, ou quando esta for responsável ou potencialmente responsável pelo mecanismo de produção de um reservatório ou jazida de petróleo e/ou gás natural.

3 Espaço Anular: espaço compreendido entre o revestimento do poço e a parede da escavação.
} 
aos gastos para construir e preparar as instalações, além de incorrerem por vários períodos futuros. Nas operações em terra (onshore), entretanto, muitas companhias assumem que o valor residual deve ser igual à soma dos custos de desmantelamento das instalações e dos custos necessários às atividades de limpeza e restauração da área, sendo que o custo líquido do desmantelamento freqüentemente é ignorado (JENNING, FEITEN e BROCK, 2000, p. 483).

Segundo Kaiser, Pulsipher e Byrd (2003, p. 39), os componentes de custos que devem ser levados em conta na estimativa dos custos de abandono de áreas produtoras de óleo e gás offshore são basicamente os seguintes:

- tamponamento e abandono dos poços;

- preparação para remoção da plataforma/ instalações, incluindo a lavagem e limpeza dos componentes, visando à eliminação de resíduos de hidrocarbonetos e outros, de modo a garantir a segurança no proces- so de corte e içamento das estruturas. O produto da lavagem deve ser descartado em local apropriado;

- esvaziamento e limpeza dos dutos, coluna por coluna, e desconexão dos dutos da estrutura. Alguns dutos são abandonados no local e enterrados no fundo do mar;

- separação e remoção dos módulos, tais como sonda de perfuração, guindaste e alojamento (topsides) do convés (deck) da plataforma se for necessário (em alguns casos, os módulos são removidos junto com o convés);

- corte e remoção dos condutores e convés;

- corte e remoção das jaquetas ${ }^{4}$ (jackets) e das estacas ${ }^{5}$;

- transporte dos equipamentos/instalações removidos para terra;

- liberação, limpeza e verificação da área após a remoção das estruturas.

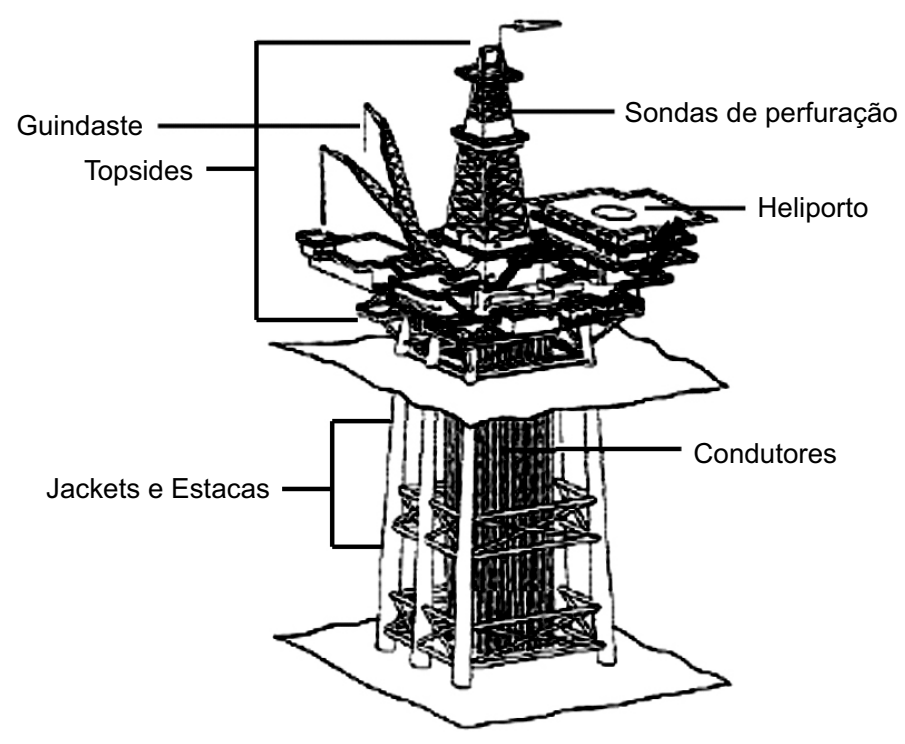

Fonte: Manago e Williamson, 1997.

Figura 2 - Plataforma Fixa Offshore

Os custos inerentes a essas atividades referem-se, basicamente, a plataformas fixas (Figura 2) e a plataformas de concreto. Para as unidades de produção marítima flutuantes, os custos de abandono serão basicamente os gastos de retirada das âncoras/amarras e aqueles decorrentes da movimentação da unidade para terra, além dos gastos com tamponamento e abandono dos poços.

Em relação ao abandono de instalações e equipamentos offshore, a cadeia de decisão leva em 
conta a melhor opção, considerando fatores como o tipo de construção, o peso, a distância para a terra, condições do tempo, características das estruturas e complexidade da remoção. As decisões quanto ao abandono das instalações offshore podem ser observadas na Figura 3 a seguir.

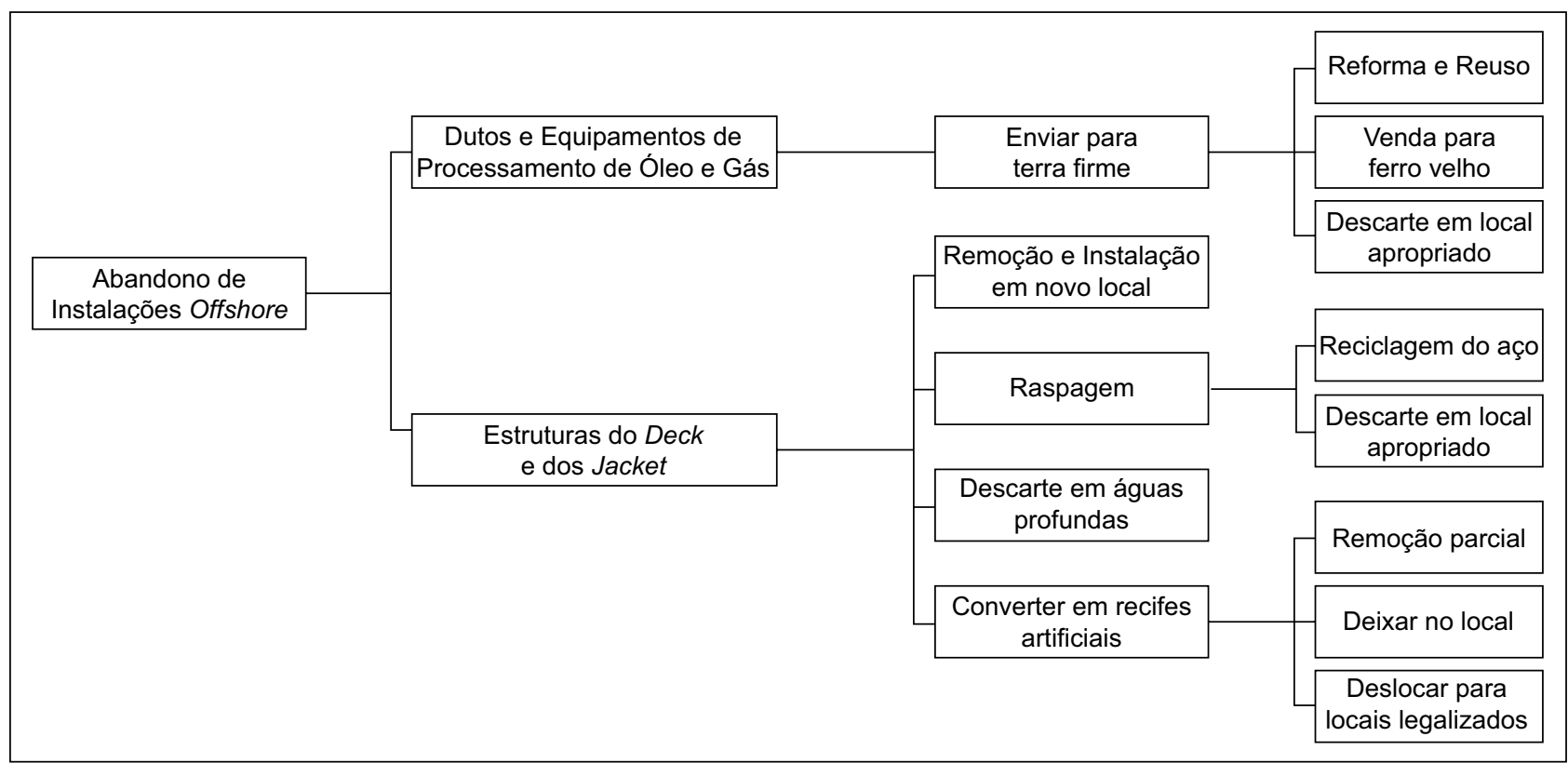

Fonte: Minerals Management Service - MMS, 2000

Figura 3 - Opções de Abandono

Não resta dúvida que o custo de abandono para a indústria petrolífera é um item fundamental nas estratégias das empresas. Segundo Pittard (1997, p. 84), estimava-se que em 1997, das 6.500 plataformas então existentes no mundo, $97 \%$ delas deveriam ser removidas completamente, sendo que os custos estimados para essas operações girariam entre US\$29 e US\$ 40 bilhões.

Dessa forma, como os valores envolvidos com as operações de desmantelamento, remoção, recuperação e abandono de poços são expressivos, é importante descrever como o custo de abandono é contabilizado pelas companhias petrolíferas, contribuindo, assim, para que os diversos usuários das informações contábeis possam compreender, adequadamente, as informações divulgadas por essas companhias.

\section{NORMAS CONTÁBEIS RELACIONADAS AO CUSTO DE ABANDONO}

A tradição norte-americana de estudos avançados de normas e práticas de contabilidade levou aquele país a desenvolver um arcabouço teórico e normativo de proeminência no cenário contábil mundial e, até mesmo, a influenciar outros países quanto a padrões de reconhecimento, mensuração e evidenciação dos elementos patrimoniais. (NIYAMA, 2005).

Em relação às obrigações de abandono de ativos de longa duração, não é diferente. Por isso, este estudo se baseia no pronunciamento do FASB, SFAS $n^{\circ} 143$ - Accounting for Asset Retirement Obligations. Adicionalmente, serão apontadas as principais orientações normativas contidas no arcabouço do International Accounting Standards Board (IASB), bem como da Comissão de Valores Mobiliários, sobre a temática.

Até junho de 2002, as companhias petrolíferas (aquelas que seguem as normas norte-americanas), contabilizavam os custos de abandono da forma que Ihes fosse mais prática e, mais especificamente, não consideravam os gastos com o desmantelamento, remoção, restauração e abandono como parte do custo do ativo (poço, equipamentos e instalações).

Mesmo seguindo as orientações do SFAS $n^{\circ}$ 19 , $\S 37$ e do Regulation $S-X$, rule $4-10$, os quais determinam que as estimativas dos custos de desmantelamento e abandono, líquidos dos valores residuais estimados, deveriam ser considerados custos amortizáveis, ou seja, levados em conta na determinação das despesas de amortização, as empresas apresentavam práticas diversas. 
De acordo com Godoy (2004) e Jenning, Feiten e Brock (2000), as empresas ou faziam uma provisão contra o lançamento como despesas do exercício dos custos de abandono futuro ou reconheciam o passivo em contrapartida a uma despesa de amortização proporcional ao nível de produção ou registravam o passivo e capitalizavam os custos de abandono de acordo com o nível de produção.

Para exemplificar, considere os dados a seguir e que a empresa reconhece a provisão para abandono no passivo na proporção relativa à produção da reserva de óleo e gás, em contrapartida a uma despesa de amortização no resultado do período.

\begin{tabular}{|l|l|}
\hline Custo de construção da plataforma & $\$ 100.000 .000$ \\
\hline Valor residual da plataforma & $\$ 2.500 .000$ \\
\hline Reservas provadas estimadas & 5.625 .000 barris \\
\hline Produção no período X1 & 56.250 barris \\
\hline Produção no período X2 & 85.920 barris \\
\hline Produção no período X3 & 62.530 barris \\
\hline Custos de abandono estimados & $\$ 2.875 .000$ \\
\hline
\end{tabular}

Fonte: Adaptado de Jenning, Feiten e Brock, 2000 e Godoy, 2004.

\section{Quadro 1 - Dados para Contabilização dos Custos de Abandono}

1) Constituição do Ativo $\left(X_{0}\right)$ :

$D$ - poços e equip. e instal. de poços. $\$ 100.000 .000$

C - caixa/bancos/financiamentos $\$ 100.000 .000$

2) Reconhecimento do Passivo $\left(X_{1}\right)$ :

2.1 Cálculo da depreciação dos custos capitalizados (método das unidades produzidas):

$\$ 100.000 .000-\$ 2.500 .000 \times 56.250$ barris $=\$ 975.000$

$$
5.625 .000 \text { barris }
$$

2.2 Cálculo do reconhecimento proporcional do passivo:

$$
\frac{\$ 2.875 .000}{5.625 .000 \text { barris }} \times 56.250 \text { barris }=\$ 28.750
$$

\subsection{Contabilizações:}

D - despesas de depreciação

C - depreciação acumulada.

$\mathrm{C}$ - passivo (provisão para abandono)

\begin{tabular}{|c|c|}
\hline $\mathrm{X} 2$ & X3 \\
\hline$\frac{\$ 96.520 .000}{5.568 .750 \mathrm{~b}} \times 85.920 \mathrm{~b}=\$ 1.489 .280$ (depreciação) & $\frac{\$ 95.035 .720}{5.482 .830 \mathrm{~b}} \times 62.530 \mathrm{~b}=\$ 1.083 .853$ (depreciação) \\
\hline$\frac{\$ 2.846 .250}{5.568 .750 \mathrm{~b}} \times 85.920 \mathrm{~b}=\$ 43.915$ (provisão) & $\frac{\$ 2.802 .335}{5.482 .830 \mathrm{~b}} \times 62.530 \mathrm{~b}=\$ 31.960$ (provisão) \\
\hline Total: \$ 1.533.195 & Total: \$ 1.115 .813 \\
\hline
\end{tabular}

3) Reconhecimento do Passivo $\left(X_{2}\right.$ e $\left.X_{3}\right)$ :

\subsection{Cálculos:}

3.2 Contabilizações:

D - despesas de depreciação

C - depreciação acumulada

C - passivo (provisão para abandono)
$\mathrm{X}_{2}$

$\$ 1.533 .195$

$\$ 1.489 .280$

$\$ 43.915$

$$
\mathrm{X}_{3}
$$

$\$ 1.115 .813$

$\$ 1.083 .853$

$\$ 31.960$ 
Pela determinação do SFAS $\mathrm{n}^{\circ} 19$, as despesas de amortização relacionadas aos custos de abandono acabavam sendo confrontadas com as receitas, em função de a amortização ser proporcional à produção da reserva. Com isso, no final da vida útil do poço, quando a produção é menor, o valor a ser levado a resultado (despesa de amortização) também será menor.

Além do mais, o grande problema em relação ao custo de abandono diz respeito à dificuldade em se estimarem, adequadamente, os gastos com o desmantelamento, remoção e restauração. Conforme Gallun, Stevenson e Nichols (1993, p. 179) apud Godoy (2004, p. 102), na prática, muitas empresas não contabilizavam os custos de abandono como passivos ou não levavam em consideração no cálculo do valor amortizado. Os motivos do não reconhecimento desses custos referem-se à dificuldade de serem estimados os custos que poderão incorrer durante muitos anos no futuro e a difícil estimação de por quanto tempo eles durarão.

Dada a diversidade de práticas contábeis que vinham dificultando a comparabilidade da posição financeira e do resultado das operações e o não reconhecimento de obrigações que atendiam à definição de passivo, além da sua não quantificação ou apresentação de forma consistente, o FASB justificou a emissão do SFAS $n^{\circ} 143$ - Accounting for Asset Retirement Obligations em 2001 e definiu as práticas contábeis aplicáveis a empresas petrolíferas (mas não somente a elas) quanto ao tratamento que deveria ser empregado em relação ao custo de abandono.

O SFAS 143 aplica-se a todas as entidades que possuem obrigações legais associadas à baixa de ativos de longo prazo resultantes da aquisição, construção, expansão e/ou da operação normal do ativo. Conforme Chewning Jr. e Mckie (2002, p. 56), são exemplos de obrigações dentro do escopo do SFAS 143: descomissionamento de instalações de geração de energia nuclear; desmantelamento e remoção de instalações de produção de óleo e gás marítima; custos de fechamento, de recuperação e de remoção associados a atividades de mineração e fundição e custos de fechamento e pós-fechamento de aterro sanitário, instalações de descarte de lixo perigoso e instalações de estocagem de combustível.

Contudo, as obrigações de baixa de ativo não podem ser confundidas com obrigações que surgem de operações impróprias ou de acidentes, como, por exemplo: obrigações resultantes de um desastre ambiental, do incêndio da fábrica etc. (op. cit., 2002, p. 56).

A norma passou a vigorar para as demonstra- ções contábeis emitidas no exercício social iniciado após 15 de junho de 2002.

A determinação básica do SFAS 143 é a de que os custos associados à baixa futura dos ativos são capitalizados como parte do valor contábil dos ativos de longo prazo relacionados à obrigação de baixa (poços e equipamentos e instalações dos poços, por exemplo) e a de o valor justo de um passivo por obrigação de baixa de ativo seja reconhecido no período em que for incorrido, se uma estimativa razoável do valor justo possa ser feita.

Com isso, o SFAS 143 introduziu a discussão sobre qual seria o valor justo para o reconhecimento de um passivo pela obrigação de baixa de ativo. Conforme o $\S 7^{\circ}$, o valor justo é o valor pelo qual aquele passivo poderia ser quitado em uma transação normal entre as partes (sem ser forçada), representando o valor de mercado dos ativos e passivos, ou pelo menos uma estimativa mais próxima dos benefícios e custos futuros esperados destes.

Segundo o FASB, o preço de mercado é a melhor opção do valor justo e serão usados como base para a quantificação do passivo relacionado à obrigação da desativação dos ativos. Caso o preço de mercado não esteja disponível (por falta de um mercado ativo, por exemplo), a estimativa do valor justo será baseada na melhor informação disponível, incluindo os valores de passivos similares e os resultados das técnicas de valor presente.

Em relação às técnicas de valor presente, o SFAS 143 aponta que tanto a técnica do fluxo de caixa tradicional, como a do fluxo de caixa esperado, pode, teoricamente, ser utilizada para a quantificação do valor justo. Contudo, a técnica do fluxo de caixa esperado é a mais adequada para uma obrigação por baixa de ativo, tendo em vista, que nessa abordagem, utiliza-se das incertezas em torno dos valores e dos prazos do fluxo de caixa futuros, com a utilização de múltiplos cenários de fluxos de caixa, que reflitam a faixa de resultados possíveis, além de uma taxa de desconto adequada à captação (taxa de juros livre de risco, ajustada ao nível de crédito da empresa) para descontar o fluxo a valores presentes.

Em junho de 2004, o FASB colocou em discussão pública uma minuta de interpretação da contabilização das obrigações por baixa de ativo exigida pelo SFAS 143, em função de que algumas questões ainda eram passíveis de dúvida por parte dos usuários e mereciam ser mais bem definidas ou clarificadas.

Como resultado, foi emitido, em março de 2005, o FASB Interpretation 47 - Accounting for Conditional Asset Retirement Obligations (FIN 47), visando sanar os questionamentos que surgiram em 
relação à aplicação do SFAS 143. Um dos questionamentos dizia respeito ao processo de cálculo das estimativas do custo de abandono. O próprio FASB reconheceu que, em alguns casos, não existem informações suficientes para estimar o valor justo de uma obrigação por baixa de ativo.

Nesse caso, se a empresa dispuser de informações suficientes para estimar razoavelmente o valor justo da obrigação de baixa de ativo, ela deve registrar o passivo no momento em que o mesmo ocorrer, caso contrário, o reconhecimento se dará somente no momento em que as informações se tornarem disponíveis para estimar o valor justo da obrigação de baixa.

Outra questão dizia respeito a se toda e qualquer obrigação resultante de ativos deve ser reconhecida ou somente aquela que encontra a definição de Passivo, tal como definido no SFAS $n^{\circ} 6$. De acordo com a decisão do FASB, contida no FIN 47 , somente aquelas obrigações que encontram a definição de Passivo estariam dentro do escopo do SFAS 143, como o próprio FASB já havia previsto em seu pronunciamento.

Contabilmente, o SFAS 143 prevê as seguintes determinações:

a) reconhecimento no ativo e passivo da obrigação por baixa de ativo

No período em que forem reconhecidos os ativos originadores da obrigação futura, deverão ser contabilizados ao custo histórico desses ativos, os custos por obrigação de baixa relacionada ao ativo. Um passi- vo de igual valor, medido pelo valor justo, também seria reconhecido em contrapartida (SFAS 143, § 11).

As provisões para o abandono (passivo) são constituídas tendo em vista onerar o resultado de hoje em função de um desembolso futuro já conhecido ou estimado e que já se sabe que a companhia incorrerá nele. Dessa forma, é justo e correto que os bens produzidos hoje e as receitas por eles geradas, já sejam diminuídos da parte que lhes cabe desse desembolso futuro. Da mesma forma que a amortização/depreciação oneram o resultado de hoje com parcelas de desembolsos passados, a provisão para abandono onera o resultado de hoje com parcelas do desembolso futuro.

No setor petrolífero, portanto, os custos de desmantelamento, remoção e restauração (custo de abandono) serão reconhecidos no passivo no momento em que os ativos geradores da obrigação (poços, equipamentos e instalações, por exemplo) também o forem.

Pelo lado do ativo, será contabilizado o mesmo montante registrado no passivo, cujo valor passará a fazer parte do custo histórico dos ativos geradores da obrigação, para todos os efeitos. A Figura 4 mostra, graficamente, o reconhecimento da obrigação no Passivo em contrapartida à contabilização no ativo.

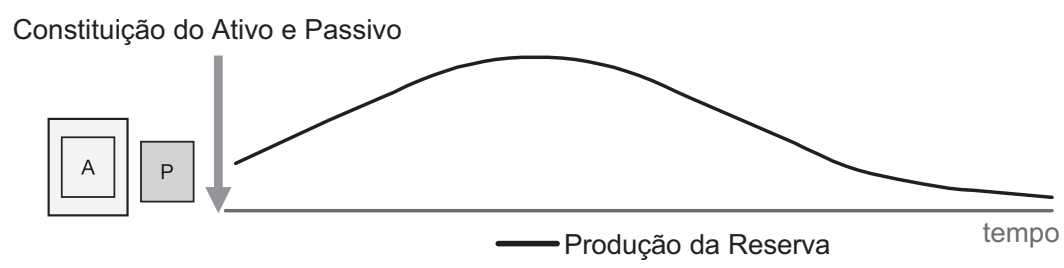

Fonte: Elaborada pelos autores.

Figura 4 - Reconhecimento da Obrigação por Baixa de Ativo

De acordo com Kieso, Weygandt e Warfield (2005, p. 638), os custos de baixa de ativos devem ser registrados como parte associada ao ativo em função de esses custos serem considerados como custos operacionais e, ainda, por serem necessários à preparação do ativo para uso futuro. Assim, um ativo específico (por exemplo, mina, plataforma de exploração de petróleo, usina nuclear) deve ser adicionado devido aos benefícios econômicos futuros que emanarem do uso produtivo desse ativo. Portanto, "os custos de baixa de ativos capitaliza- dos não devem ser reconhecidos separadamente em conta específica porque não existirá no futuro benefício econômico que possa ser associado com esses custos sozinhos".

Em se tratando da valoração do passivo pelo valor justo, tem-se que para a indústria petrolífera, o preço de mercado não é o mais apropriado, devido aos custos de desmantelamento, remoção e restauração serem díspares e dependerem de diversos fatores.

Conforme afirma Kaiser (2005, p. 45), os custo 
de abandono do poço, da remoção da infraestrutura da plataforma e da restauração do local, dependem de fatores como as características físicas do poço e estruturas, da localização, do tipo de contrato, das opções disponíveis, da preferência pelos operadores, das condições de mercado, da ocorrência e duração de eventos exógenos (eventos climáticos) e das estratégias de negociação. Por isso, o valor estabelecido para o passivo será mais adequado pela abordagem do fluxo de caixa esperado, do que pelo preço de mercado, dado que cada abandono envolve custos diferentes.

O reconhecimento da obrigação poderá ser efetuado em mais de um período contábil, se o reconhecimento dos ativos relacionados ao poço de produção de petróleo e gás natural ocorrerem em mais de um período contábil. Assim, os passivos subseqüentes serão considerados como um nível adicional do passivo original e cada nível será quantificado, inicialmente, pelo seu valor justo.

Como exemplificam Jenning, Feiten e Brock (2000, p. 490), a reserva de petróleo não desenvolvida, por definição exigirá novos poços ou novos gastos antes de ela ser classificada como reserva provada desenvolvida. Ao longo do desenvolvimento desses novos poços, associados com a transferência de reserva não desenvolvida para desenvolvida, surgem obrigações adicionais para baixar desses ativos no futuro. Dessa forma, o passivo será controlado "por níveis de agregação". b) variações no passivo decorrentes da passagem de tempo

Nos períodos subseqüentes à quantificação inicial do passivo, as companhias deverão reconhecer as variações periódicas nesse passivo resultante da passagem de tempo. Para tanto, as companhias quantificarão as variações aplicando o método de alocação de juros ao valor do passivo, no início de cada período. A taxa de juros será a taxa de juros livre de risco ajustada pelo nível de crédito da empresa, que foi utilizada na estimativa do fluxo de caixa esperado para quantificar a obrigação.

O valor dos juros será considerado como um aumento no valor contábil da obrigação em contrapartida a uma despesa classificada como item operacional (SFAS 143, $\S \S 13$ e 14), ou seja, o valor registrado no passivo será corrigido, mensalmente, pela simples atualização temporal do valor presente e só será reduzido na época do efetivo abandono de cada poço de produção de petróleo e gás, desmantelamento e remoção dos equipamentos e instalações e restauração do local. Graficamente, a atualização temporal do passivo pode ser observada na Figura 5.

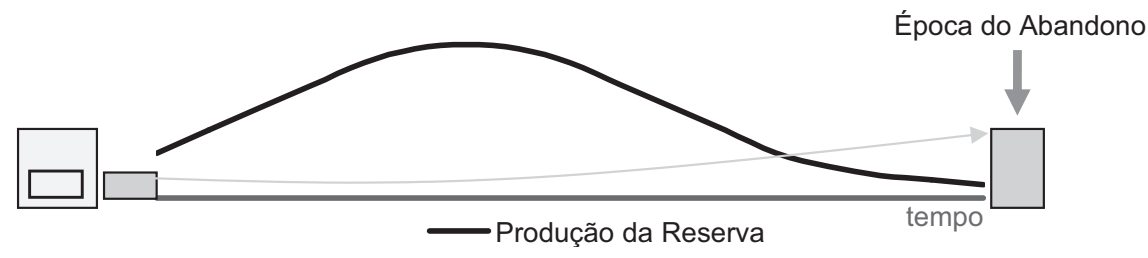

Fonte: Elaborada pelos autores.

Figura 5 - Atualização Temporal do Passivo

Por essa sistemática, a evidenciação dos eventos inerentes às atividades de desmantelamento, remoção e restauração apresentará melhor grau de disclosure, ou seja, o passivo estará, na proximidade do abandono, espelhando a melhor estimativa possível dos custos de abandono, ao contrário do que ocorria anteriormente, cuja constituição do passivo se dava proporcionalmente à produção da reserva.

c) depreciação/amortização do ativo constituído com base na obrigação de baixa Tendo em vista que o reconhecimento da obrigação de baixa de ativo tem como con- trapartida no ativo um custo de abandono capitalizado como parte do custo histórico do ativo que originou a obrigação, um efeito subseqüente da adoção do SFAS 143 diz respeito às questões relacionadas à depreciação/amortização dos ativos de longa duração da entidade.

De acordo com Stickney e Weil (2001), em função de os ativos representarem benefícios futuros, o seu custo de aquisição, construção ou desenvolvimento deve ser alocado aos diversos períodos em que a empresa se beneficiará deles. Esse pro- 
cesso geral de alocação dos custos é denominado de amortização.

Hendriksen e Van Breda (1999) argumentam que a principal ênfase do processo de depreciação/amortização reside no cálculo de um débito periódico a ser vinculado às receitas a serem registradas em cada período. Esse débito será alocado às despesas como custo do período ou como custo de um produto.

De acordo com ludícibus (2000, p. 58), “[...] não se pode reconhecer a receita sem que a despesa associada seja delineada, mesmo que apenas como estimativa [...]" e o elemento fundamental no reconhecimento da receita e na apropriação das despesas não é seu recebimento ou pagamento, mas o ganho da receita e o fato de se ter incorrido a despesa.

Dessa forma, o raciocínio que envolve o reconhecimento de uma obrigação futura de acordo com o SFAS 143, é o de que, das receitas geradas, hoje, pela empresa, deve ser deduzida a parcela que lhes cabe do desembolso futuro. Com isso, o custo de abandono capitalizado deve ser depreciado/amortizado mensalmente, para ser confrontado com a receita correspondente.

A sistemática imposta pelo SFAS 143 leva ao reconhecimento de duas parcelas de despesas na demonstração do resultado: (a) as despesas referentes à atualização do valor justo da obrigação pela passagem do tempo, que será classificada como um item operacional e foi visto anteriormente e (b) a despesa com depreciação/amortização dos custos de abandono capitalizados no ativo, classificada também como item operacional.

O SFAS 143, § 11, fala de um método sistemático e racional para alocação da despesa (despesa de depreciação/amortização) ao resultado. De acordo com ludícibus (2000, p. 192), a amortização do custo é o "racional" utilizado, pois não se trata de um processo valorativo, mas meramente alocativo de custos passados para despesa dos períodos futuros, de forma sistemática e racional. Entretanto, o autor entende que se pode, talvez, assegurar muito mais a sistematicidade do que a racionalidade.

Dessa forma, o que variará será a maneira como os custos serão alocados (amortizados) aos períodos que proporcionam os benefícios futuros. Decorre daí a existência de diversos métodos de cálculo da depreciação/amortização, todos de acordo com os princípios contábeis.

De acordo com Hendriksen e Van Breda (1999), o método racional e sistemático mais comum é a depreciação linear, por ser o mais simples de se compreender e aplicar. Em se tratando do método das unidades produzidas, Weygandt, Kieso e Kimmel (2005), argumentam que esse método, em vez de expressar a vida útil do bem como um intervalo de tempo, a vida útil é expressa em termos do total de unidades de produção ou da utilização esperada do ativo. Ele serve perfeitamente para depreciação de máquinas e equipamentos, mas não é adequado, por exemplo, para ativos como edificações ou mobiliário, pois a depreciação desses ativos é mais em função do tempo do que da utilização.

Ainda segundo os autores, quando a produtividade do ativo varia significativamente de um período para outro, o método das unidades produzidas resulta em uma meIhor confrontação das despesas com as receitas e, ainda, que esse método é geralmente utilizado para calcular a exaustão, pois a exaustão periódica é, em geral, função das unidades extraídas durante $o$ ano, como é o caso de um campo de petróleo. Por isso, o método comumente utilizado pela indústria petrolífera é o método das unidades produzidas.

d) revisões no prazo ou no valor da estimativa original

As variações decorrentes das revisões no prazo ou no valor da estimativa original da obrigação por baixa de ativo serão reconhecidas no valor do passivo e, conseqüentemente, do ativo. Conforme o SFAS 143 , $\S 15$, essas variações serão reconhecidas como acréscimos ou decréscimos: (a) no valor contábil do passivo de uma obrigação por baixa de ativo e (b) no respectivo custo por baixa de ativo, capitalizado como parte do valor contábil do ativo que originou a obrigação.

e) divulgação das informações

As empresas deverão divulgar as seguintes informações relacionadas às obrigações por baixa de ativo (SFAS 143, § 22): 1) descrição geral das obrigações por baixa de ativos e dos ativos associados a essas obrigações; 2) o valor justo dos ativos destinado à quitação das obrigações por baixa 
de ativo; 3) reconciliação do valor contábil agregado inicialmente e no final das obrigações por baixa de ativos, demonstrando separadamente as variações atribuíveis a: (i) passivos incorridos no período atual; (ii) passivos quitados no período atual; (iii) despesa adicional e (iv) revisões nos fluxos de caixa estimados; sempre que houver uma variação significativa em um ou mais dos quatro componentes acima, durante o período contábil.

f) ajuste de períodos anteriores

Por ocasião da aplicação inicial do SFAS 143 , as empresas deverão reconhecer os seguintes itens em suas demonstrações financeiras (SFAS 143, § 25): 1) o passivo de qualquer obrigação por baixa de ativos existentes, ajustados por provisão cumulativa até a adoção do SFAS 143; 2) o custo por baixa de ativo capitalizado como acréscimo do valor contábil do ativo originador da obrigação; 3) a depreciação/amortização acumulada desse custo capitalizado.

Os valores resultantes da aplicação inicial serão quantificados utilizando-se as informações atuais, ou seja, até a data da adoção da norma, as premissas atuais e as taxas de juros atuais. $\mathrm{O}$ valor reconhecido como custo capitalizado será quantificado na data em que o ativo que originou a obrigação foi adquirido. O passivo acumulado e a depreciação e amortização acumuladas serão quantificadas pelo período de tempo desde a data em que o passivo deveria ter sido reconhecido se a norma estivesse em vigor, até a data de adoção da norma.

Com isso, as empresas reconheceriam um ajuste de períodos anteriores provenientes de mudanças de prática contábil. $O$ valor a ser reportado seria a diferença entre os valores, se houvesse, reconhecidos na demonstração financeira anterior e aqueles reconhecidos na demonstração financeira sob a égide do SFAS 143.

Para exemplificar os procedimentos definidos pelo SFAS 143, considerem-se os mesmos dados do Quadro 1 e que o valor das estimativas dos custos de abandono (valor futuro da obrigação) trazido a valor presente por uma taxa de desconto de $8 \%$ a.a. e utilizando-se o método do fluxo de caixa descontado para um período de 15 anos, é de $\$ 906.320$. As contabilizações ficariam da seguinte forma:

1) Constituição do Ativo $\left(X_{0}\right)$ :

$D$ - poços e equip. e instal. de poços $\$ 100.906 .320$

C - caixa/bancos/financiamentos $\$ 100.000 .000$

C - passivo (provisão para abandono). $\$ 906.320$

2) Cálculo da depreciação dos custos capitalizados $\left(X_{1}\right)$ :

$\$ 100.906 .320-\$ 2.500 .000 \times 56.250$ barris $=\$ 984.063$

5.625 .000 barris

D - despesas de depreciação

$\$ 984.063$

C - depreciação acumulada. $\$ 984.063$

3) Atualização do Passivo pela passagem de tempo $\left(X_{1}\right)$ :

$D$ - despesa (item operacional). $\$ 72.506$

C - passivo (provisão para abandono) $\$ 72.506$

4) Registros em $X_{2}$ e $X_{3}$ :

4.1 Cálculos:

\begin{tabular}{|c|c|}
\hline $\mathbf{X} 2$ & $\mathbf{X 3}$ \\
\hline$\frac{\$ 97.422 .257}{5.568 .750 \mathrm{~b}} \times 85.920 \mathrm{~b}=\$ 1.503 .124$ (depreciação) & $\frac{\$ 95.919 .133}{5.482 .830 \mathrm{~b}} \times 62.530 \mathrm{~b}=\$ 1.093 .928$ (depreciação) \\
\hline$\$ 906.320(1,08)^{2}-\$ 906320=\$ 150.812$ (provisão) & $\$ 906.320(1,08)^{3}-\$ 906320=\$ 235.382$ (provisão) \\
\hline
\end{tabular}

4.2 Contabilizações:

D - despesas de depreciação

C - depreciação acumulada

$\mathrm{D}$ - despesa (item operacional)

C - passivo (provisão para abandono)
$\mathrm{X}_{2}$

$\$ 1.503 .124$

$\$ 1.503 .124$

$\$ 150.812$

$\$ 150.812$
$\mathrm{X}_{3}$

$\$ 1.093 .928$

$\$ 1.093 .928$

$\$ 235.382$

$\$ 235.382$ 
Dessa forma, contabilmente, o valor total da estimativa do custo de abandono é reconhecido de uma única vez no passivo, no momento em que a obrigação é criada, ante ao que era registrado anteriormente com a estimativa do custo de abandono provisionado mensalmente com base numa taxa proporcional ao quociente da produção realizada no mês anterior pela reserva remanescente do campo.

Constituído o passivo, o saldo provisionado será utilizado para o abandono parcial dos poços e instalações durante a vida útil do campo ou para o abandono total do campo (com o desmantelamento e remoção da plataforma, por exemplo), quando ocorrer a extinção das reservas de hidrocarbonetos.

Em se tratando do SFAS 143, a sistemática imposta pela norma, de que a constituição do passivo seja feita de uma só vez, pelo valor total, é coerente à medida que uma obrigação deve ser reconhecida em função de seu fato gerador, que nesse caso, é o reconhecimento inicial do ativo que criou uma obrigação futura para a empresa. Dessa forma, a empresa evidenciará, desde o início, que ela possui uma obrigação futura valorada pela melhor estimativa disponível. Esse entendimento vai ao encontro do que afirmam Jenning, Feiten e Brock (2000, p. 485), de que "as empresas não devem retardar o reconhecimento da obrigação, mesmo baseada numa simples estimativa do valor futuro".

Já em relação à atualização do passivo, com a sistemática de atualização pela passagem de tempo, quando chegar a época do efetivo abandono do ativo, o passivo e o resultado do período estariam espelhando a melhor estimativa possível dos gastos com o abandono na proximidade desse evento, se comparado com o passado, com a atualização de acordo com a produção.

\subsection{Posições do IASB e da CVM}

Em relação às normas do International Accounting Standards Board (IABS), o tratamento a ser dispensado no reconhecimento de uma obrigação de baixa de ativos de longa duração está baseada em três pronunciamentos: o International Accounting Standards $n^{\circ} 16$ (IAS 16), que trata do ativo imobilizado; o International Accounting Standards $\mathrm{n}^{\circ} 37$ (IAS 37), que trata da provisão de ativos e passivos contingentes; e o International Financial Reporting Interpretations Committee $\mathrm{n}^{\circ} 1$ (IFRIC 1), que trata das mudanças na existência de descomissionamento, restauração e obrigações similares.

De acordo com o IAS 37, §14, uma provisão deve ser reconhecida quando: (a) uma entidade tem uma obrigação presente (legal ou construtiva) como conseqüência de um evento passado; (b) é provável que recursos sejam exigidos para liquidar a obrigação e (c) o montante da obrigação possa ser estimado com suficiente segurança. Se qualquer uma dessas condições não for atendida, a provisão não deve ser reconhecida.

Uma obrigação legal é aquela que deriva de um contrato (por meio de termos explícitos ou implícitos), de uma lei ou de outro instrumento fundamentado em lei e uma obrigação construtiva é aquela que surge quando uma entidade, mediante práticas do passado, políticas divulgadas ou declarações feitas, cria uma expectativa válida por parte de terceiros e, por conta disso, assume um compromisso. (IAS 37, §10).

Dessa forma, caso exista uma obrigação legal ou construtiva que exija de uma entidade, no futuro, a desmontagem, remoção, desmobilização, desativação e recuperação ambiental envolvendo ativos de longa duração e essa obrigação possa ser estimada, uma provisão deve ser reconhecida pela entidade.

O montante a ser reconhecido como provisão deve ser a melhor estimativa do desembolso exigido para liquidar a obrigação presente na data do balanço e essa estimativa é o montante que uma entidade pagaria para liquidar a obrigação na data do balanço ou para transferí-la para terceiros naquela data. (IAS 37, §36).

Em relação ao valor presente, quando o efeito do valor do dinheiro no tempo for relevante, o montante de uma provisão deve ser o valor presente dos desembolsos que se espera que sejam exigidos para liquidar a obrigação. Dessa forma, o valor contábil de uma provisão aumentará a cada período para refletir a passagem de tempo. (IAS 37, §45).

Quanto à contrapartida da provisão para abandono, o IAS 37 é omisso, a não ser pelo exemplo 3 constante do apêndice $C$ da norma. Nesse caso, o IAS 16 disciplina essa situação. O parágrafo 16, letra c, do IAS 16, prevê que o custo do ativo imobilizado deve compreender, dentre outros, a estimativa inicial dos custos de desmantelamento e remoção do ativo e, ainda, aqueles referentes à recuperação ambiental da área onde o ativo estava instalado. Esse custo comporá, inclusive, a base depreciável do ativo.

Por fim, o IFRIC 1 prescreve o tratamento a ser dispensando pelas empresas em relação às mudanças decorrentes nas estimativas iniciais dos custos de descomissionamento e restauração baseadas em fluxo de caixa, mudanças na taxa de desconto em função das condições de mercado e que a contrapartida da atualização do passivo deve ser considerada como custo financeiro na demonstração de resultados, quando incorridos. 
A Comissão de Valores Mobiliários, tendo por base a importância e a necessidade de que as práticas contábeis brasileiras sejam convergentes com as práticas contábeis internacionais, emitiu a Deliberação CVM 489/05, que aprovou o Pronunciamento do IBRACON NPC $n^{\circ} 22$, que trata da definição dos critérios de reconhecimento e bases de mensuração aplicáveis a provisões, contingências passivas e contingências ativas. A Deliberação da CVM espeIha em sua quase totalidade as constantes do IAS 37 , apresentadas anteriormente.

A ressalva encontrada na norma da CVM é a de que o ajuste a valor presente previsto na norma, mais especificamente nos parágrafos 37,38 e 45, deverá ser efetuado apenas se requerido por uma norma específica que se refira à provisão, ou quando da edição de norma que dê legitimidade à aplicação desse conceito nas práticas contábeis adotadas no Brasil.

Quanto à contrapartida do passivo, da mesma forma como o IAS 37, não existe previsão clara, apenas indireta quando apresenta um exemplo constante do Anexo II, item 2c. Recorrendo a outra norma brasileira, na Resolução do Conselho Federal de Contabilidade $\mathrm{n}^{\circ} 1.025$, de 15 de abril de 2005, que aprovou a Norma Brasileira de Contabilidade NBC T 19.1 - Imobilizado, tem-se a seguinte determinação: o custo de um bem do imobilizado compreende: "[...] (c) o custo estimado para desmontar e remover o ativo e restaurar o local no qual está localizado, quando existir a obrigação futura para a entidade." (NBC T 19.1, item 19.1.5.1).

Assim, apesar de algumas particularidades, 0 SFAS 143 está alinhado às normas internacionais, da mesma forma que as normas brasileiras.

\section{CONSIDERAÇÕES FINAIS}

A edição do SFAS 143 impôs uma extensa mudança em como as companhias devem contabilizar suas obrigações por baixa de ativo. Particularmente para empresas de capital intensivo, como as companhias petrolíferas, as imposições normativas do SFAS 143, exigiram análises significativas, mudanças processuais e, dependendo da prática contábil adotada antes do SFAS 143, alterações materiais nas demonstrações financeiras.

Outro aspecto decorrente da adoção do SFAS 143 é o de que o processo de elaboração da estimativa do custo de abandono sofrerá impactos principalmente na etapa de inventário de poços, equipamentos e instalações, em função do nível de controle requerido pelas variações nas estimativas que resultarão na quantificação do valor justo do passivo e suas conseqüências nas revisões do prazo ou no valor da estimativa original. Com isso, controles adicionais serão exigidos para identificação de todos os ativos que produzirão obrigações pela baixa de ativos.

Para o FASB, os benefícios provenientes do SFAS 143 justificam e superam os esforços e custos da mudança e ainda fornecem mecanismos que garantam que as demonstrações financeiras das companhias reflitam mais claramente a realidade econômica das obrigações por baixa de ativo.

Com o reconhecimento de uma obrigação futura, mesmo em termos de valores estimados, a situação patrimonial da empresa será mais bem evidenciada, aumentando o grau de disclosure das informações. Além disso, reconhecendo o passivo no momento do fato gerador, ou seja, no momento inicial da ativação do bem, logo de início fica evidenciado que a empresa interveio no meio ambiente e terá, no futuro, a obrigação de deixá-lo nas condições pré-existentes, com a remoção de seus ativos fixos e restauração do meio ambiente.

A orientação dada pelo SFAS 143 veio regularizar uma situação em que diversas práticas contábeis eram empregadas e que acabavam prejudicando a comparabilidade das informações divulgadas. Além do mais, com o reconhecimento imediato desse custo futuro inevitável, as análises estratégicas das empresas petrolíferas ficarão mais apuradas, pois será possível distribuir o custo ao longo da vida útil do projeto por meio das parcelas de depreciação/amortização e da atualização do valor presente da obrigação, atendendo, também, o princípio da confrontação das despesas com as receitas.

Como sugestões para estudos futuros, uma pesquisa interessante e complementar a este estudo seria verificar, empiricamente, o impacto da adoção do SFAS 143 pelas maiores companhias petrolíferas e se elas evidenciaram, adequadamente, essas mudanças em suas demonstrações financeiras.

Outros estudos poderiam ser delineados como: (a) definição da taxa livre de risco, ajustada ao nível de crédito das empresas, representativa do setor petrolífero; (b) implicações do teste de impairment na sistemática de reconhecimento de uma obrigação por baixa de ativo; (c) estudo empírico das atividades de desmantelamento, remoção e restauração de ativos destinados à produção de óleo e gás no Brasil, visando estimar um nível adequado desses custos (custos de abandono). Tal estudo, particularmente, mostra-se relevante à medida que hoje, no Brasil, o número de empresas que está atuando no segmento de E\&P se mostra crescente em função da quebra do monopólio do petróleo. Assim, estudos com essa abordagem poderiam contribuir para as atividades dos engenheiros, gerentes de proje- 
tos e outros profissionais envolvidos na avaliação da viabilidade econômica de um projeto petrolífero e (d) impactos inerentes à adoção do SFAS 143, ante as exigências do SFAS $n^{\circ} 69$ - Divulgação das Atividades de Produção de Óleo e Gás.
Com isso, espera-se que este estudo desperte o interesse de pesquisadores sobre os assuntos aqui abordados, bem como outros inerentes à contabilidade de empresas petrolíferas no Brasil e no mundo.

\section{REFERÊNCIAS BIBLIOGRÁFICAS}

ANP - Agência Nacional do Petróleo. Portaria ANP $n^{\circ}$ 25, de 6 de março de 2002.

ANP - Agência Nacional do Petróleo. Portaria ANP $n^{\circ}$ 114, de 25 de julho de 2001.

ATKINSON, Anthony A.. Life-cycle costing. CMA Magazine. v. 64, n. 6, jul./aug. 1990 .

CFC - Conselho Federal de Contabilidade. Resolução CFC $n^{\circ}$ 1.025, de 15 de abril de 2005. Aprova a NBC T 19.1 Imobilizado.

CHEWNING JR., E. G.; MCKIE, A.. Accounting for asset retirement obligations. The CPA Journal. New York; v. 72, n. 5, p. 5658,2002

COGAN, S.. Custos e preços: formação e análise. São Paulo: Pioneira, 2002.

EPSTEIN, M. J.. Accounting for product take-back. Management Accounting. v. 78, n. 2. Aug., 1996.

CVM - Comissão de Valores Mobiliários. Deliberação CVM $n^{\circ}$ 489, de 03 de outubro de 2005.

FASB - Financial Accounting Standards Board. FASB Interpretation 47 - Accounting for Conditional Asset Retirement Obligations. USA, 2005.

FASB - Financial Accounting Standards Board. Statements of Financial Accounting Standards $n^{\circ} 143$ - Accounting for Asset Retirement Obligations. USA, 2001.

FASB - Financial Accounting Standards Board. Statements of Financial Accounting Standards $n^{\circ} 19$ - Financial Accounting and Reporting by Oil and Gas Producing Companies. USA, 1977.

GIL, A. C.. Como elaborar projetos de pesquisa. $3^{a}$ ed. São Paulo: Atlas, 1996.

GODOY, C. R.. Evidenciação contábil e as avaliações pelo fluxo de caixa descontado e pela teoria de opções: um estudo aplicado à indústria petrolífera mundial. 2004. Tese (Doutorado em Contabilidade e Controladoria) - Departamento de Contabilidade e Atuária, Faculdade de Economia, Administração e Contabilidade da Universidade de São Paulo, São Paulo.

HENDRIKSEN, E. S.; VAN BREDA, M. F.. Teoria da contabilidade. São Paulo: Atlas, 1999.

HORNGREN, C. T.; DATAR, S. M.; FOSTER, G.. Contabilidade de custos: uma abordagem gerencial. $11^{a}$ ed., v. 1. São Paulo: Prentice Hall, 2004.
IASB - International Accounting Standards Board. International Financial Reporting Interpretations Committee $\mathrm{n}^{\circ} 1$ - Changes in existing decommissioning, restoration and similar liabilities. 2004.

IASB - International Accounting Standards Board. International Accounting Standards $\mathrm{n}^{\circ} 37$ - Provisions, contingent liabilities and contingent assets. Revisado em 2004.

IASB - International Accounting Standards Board. International Accounting Standards $\mathrm{n}^{\circ} 16$ - Property, plant and equipment. Revisado em 2004.

IUDÍCIBUS, S.. Teoria da Contabilidade. $6^{\mathrm{a}}$ ed., São Paulo: Atlas, 2000.

JENNING, D. R.; FEITEN, J. B.; BROCK, H. R.. Petroleum accounting: principles, procedures $\&$ issues. $5^{a}$ ed., Denton, Texas: PricewaterhouseCoopers/Professional Development Institute, 2000.

KAISER, M. J.. FASB 143 rules will change decommission liability. Oil \& Gas Journal. Tulsa, Oklahoma; v. 103, n. 10, p. 43-49, 2005.

KAISER, M. J.; PULSIPHER, A. G.; BYRD, R. C.. Study estimates Gulf of Mexico decommissioning costs. Oil \& Gas Journal. Tulsa, Oklahoma; v. 101, n. 38, p. 39-47, 2003.

KIESO, D. E.; WEYGANDT, J. J.; WARFIELD, T. D.. Intermediate accounting: 2005 FASB update plus free problem solving guide. $11^{\text {a }}$ ed., New York: J. Wiley, 2005.

KAPLAN, R. S.; COOPER, R.. Cost and Effect: using integrated cost systems to drive profitability and performance. Boston, Massachusetts: Harvard Business School, 1998.

MMS - US Minerals Management Service. State of the Art of Removing Large Platforms Located in Deep Water. Twachtman Snyder \& Byrd, Inc. Houston, Texas, 2000.

MANAGO, F.; WILLIAMSON, B.. Decommissioning and Removal of Oil and Gas Facilities Offshore California: Recent Experiences and Future Deepwater Challenges. MMS OCS Study 98-0023. 269 pp, 1997.

NIYAMA, J. K.. Contabilidade internacional. São Paulo: Atlas, 2005.

PERES JR. J. H.; OLIVEIRA, L. M. de; COSTA, R. G.. Gestão estratégica de custos. São Paulo: Atlas, 1999.

PITTARD, A.. Field abandonment costs vary widely worldwide. Oil \& Gas Journal. Tulsa, Oklahoma; v. 95, n. 11, p. 84-91, 1997. 
SEC - Securities and Exchange Commission. Regulation S-X Rule 4-10. USA, 1975.

SILVA, C. E. V.. Uma análise da mudança das práticas contábeis, ocorridas em 1999, relativas às atividades de exploração e produção de petróleo: o caso Petrobras S/A. 2004. Dissertação (Mestrado em Ciências Contábeis). FACC/UFRJ - RJ.

STICKNEY, C. P.; WEIL, R. L.. Contabilidade financeira: uma introdução aos conceitos, métodos e usos. São Paulo: Atlas, 2001.
THOMAS, J. E.. Fundamentos da engenharia de petróleo. Rio de Janeiro: Interciência/Petrobras, 2001.

WEYGANDT, J. J.; KIESO, D. E.; KIMMEL, P. D.. Contabilidade financeira. $3^{\text {a }}$ ed. Rio de Janeiro: LTC, 2005.

\section{Endereço dos autores:}

Universidade Federal do Rio de Janeiro

FACC

Av. Brigadeiro Trompowski, s/n $\mathrm{n}^{\circ}$ Cidade Universitária

Rio de Janeiro - RJ

21.941-590 